\title{
Análise funcional como estratégia para a tomada de decisão em psicoterapia infantil
}

\author{
Functional analysis as a decision-making \\ strategy in child psychotherapy
}

\author{
Cynthia Borges de MOURA ${ }^{1}$ \\ Renata GROSSI \\ Patrícia HIRATA ${ }^{\prime}$
}

\begin{abstract}
Resumo
Este artigo apresenta a sistematização dos dados provenientes da condução de um processo psicoterapêutico infantil, a partir do modelo de análise funcional descritiva proposto por Sturmey, 1996. O trabalho apresenta a descrição do caso, a avaliação realizada, as análises funcionais de cada etapa da intervenção, os objetivos e estratégias de tratamento, selecionadas com base nas análises realizadas, e os resultados obtidos. Discute-se, a partir da sistematização apresentada, qual a contribuição da análise funcional descritiva para a compreensão do processo de tomada de decisão em psicoterapia infantil. Descrições das tomadas de decisões dos terapeutas e suas consequências para a condução do processo da criança parecem trazer contribuições relevantes para a prática do terapeuta comportamental infantil, por explicitar os fundamentos das ações realizadas.
\end{abstract}

Unitermos: Análise funcional. Psicologia infantil. Psicoterapia infantil.

\begin{abstract}
The aim of this study is to systematize the data resulting from carrying out a child psychotherapy process in accordance with the descriptive functional analysis proposed by Sturmey, 1996. This work presents the case description, the assessment, the functional analyses of each phase of the procedure, the objectives and the treatment strategies, selected on the basis of the analyses conducted, and also the results obtained. Based on the systematization presented, the contribution of the descriptive functional analysis to the child psychotherapy decisionmaking process is discussed. Describing the therapists' actions of decision-making and the consequences for the management of the process on the child, seem to contribute significantly to the practice of child behavioral therapy. The reason for this seems to be the explanation of the theoretical basis of the therapist's actions.
\end{abstract}

Uniterms: Functional analysis. Child psychology. Child psychodrama.

Uma tarefa comum com a qual se defronta qualquer terapeuta é a avaliação de um problema clínico de modo a determinar a intervenção apropriada para modificar os comportamentos problemáticos do cliente (Haynes, Leisen \& Blaine, 1997; Kodak, Grow \& Northup,
2004; Sturmey, 1996). Frequentemente os clínicos se defrontam com questões que envolvem tomadas de decisão: quais informações coletar, como delinear o problema, como agir terapeuticamente e avaliar as mudanças alcançadas.

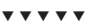

1 Universidade Estadual de Londrina, Centro de Ciências Biológicas, Departamento de Psicologia Geral e Análise do Comportamento. Campus Universitário, Caixa Postal 6001, 86051-990, Londrina, PR, Brasil. Correspondência para/Correspondence to: C.B. MOURA. E-mail: <cynthia-moura@hotmail.com.br>. 
Descrever precisamente o que os terapeutas fazem em sessão, e como o fazem, é um desafio para os estudos em psicoterapia. Pouco se conhece sobre as variáveis importantes que direcionam as decisões terapêuticas. Ou seja, as variáveis relevantes que levam um terapeuta a decidir por tomar uma direção ou outra dentro da condução de um tratamento ainda é tópico de estudo e discussão (Hagopian et al., 1997).

Tais questões também se estendem à terapia infantil (Moura \& Venturelli, 2004). Compreender o que acontece quando uma criança entra em terapia implica, entre outras coisas, que os terapeutas relatem o que fazem em sessão e por que o fazem, como optam por intervir, dadas as características da criança e de seus problemas, e como mudam o foco da intervenção a partir dos resultados que vão alcançando, rumo às metas finais de melhora.

Segundo Sturmey (1996), a análise funcional, como um quadro de referência para a análise clínica comportamental, pode trazer alguma luz a estas questões, auxiliando na identificação dos possíveis efeitos, tanto das estratégias de tratamento sobre o comportamento do cliente quanto dos comportamentos do cliente sobre a tomada de decisão do terapeuta. Assim, tratando-se de terapia infantil, podem-se levantar hipóteses que norteiem a condução do processo terapêutico, por meio da identificação dos antecedentes e das consequências dos comportamentos da criança nas interações com o terapeuta.

Nesse sentido, este trabalho propôs realizar a sistematização de um processo psicoterapêutico infantil, a partir do modelo de análise funcional descritiva (Sturmey, 1996). Apresentam-se a avaliação do caso, as análises funcionais de cada etapa, os objetivos e estratégias de tratamento, selecionadas a partir das análises realizadas, e os resultados obtidos. Espera-se, com isso, contribuir para a compreensão do processo de condução e tomada de decisão em psicoterapia infantil, trazendo contribuições relevantes para a prática do terapeuta que trabalha com crianças.

\section{Análise funcional para avaliação e tratamento de casos clínicos}

De acordo com Skinner (1974), a análise das 174 variáveis externas das quais o comportamento é função pode ser chamada de análise funcional. O comportamento de um indivíduo é a variável dependente, e as variáveis independentes são as condições externas das quais o comportamento é função. Um comportamento sempre é controlado por um estímulo e seguido por uma consequência que, dependendo de cada indivíduo, tende a fortalecer ou enfraquecer o comportamento.

A análise funcional baseia-se no estudo da relação entre variáveis dependentes e independentes e enfatiza a importância da relação de contingência que deve existir entre uma variável e outra, estabelecendo uma dependência entre os eventos que antecedem o comportamento, o próprio comportamento e as consequências do mesmo (Costa \& Marinho, 2002; Meyer, 1997; Sturmey, 1996).

Ao identificar as variáveis e explicitar as contingências que controlam o comportamento, pode ser possível levantar hipóteses acerca da aquisição e manutenção dos repertórios considerados problemáticos, para os quais poderia ser planejada a possibilidade de aquisição de novos comportamentos (Grossi, 2002).

Independentemente de se estudar um ou vários problemas, a análise funcional pode auxiliar na determinação da função do comportamento, além de conseguir estabelecer quais contingências o controlam e o mantêm. Para isso, o terapeuta utiliza-se da história passada do cliente, do seu comportamento atual e da sua relação com o ambiente; assim, pode-se proceder a uma avaliação não somente da queixa, mas dos padrões comportamentais apresentados pelo cliente e, consequentemente, de todo o processo terapêutico (Delitti, 1997).

Ainda segundo Sturmey (1996), além de se usar a análise funcional para realizar o diagnóstico comportamental e levantar possíveis causas de um comportamento, deve-se testá-la por meio de hipóteses. Assim, o autor coloca em evidência que a análise funcional é utilizada para avaliar o tratamento tanto no início quanto no meio, pois quando cada hipótese é formulada e testada ocorre a avaliação dos procedimentos clínicos, favorecendo a implementação ou a modificação do tratamento ministrado (Kodak et al., 2004). Existe, então, uma formulação inicial, que é testada, seguida de novas formulações que são igualmente submetidas a testes e revisadas no decorrer do tratamento. Com isso, é possível identificar se as hipóteses levantadas foram efetivas ou não, como foi abordado neste estudo. 
Para que uma intervenção obtenha êxito, é necessário que uma avaliação comportamental acompanhe todo o processo de tratamento e que os procedimentos, progressos e resultados sejam continuamente reavaliados, a fim de que as mudanças necessárias possam ser realizadas no foco da intervenção, quando esta não surtir o efeito desejado.

A análise comportamental supõe um esquema conceitual que guia a formulação e exame das hipóteses para alcançar o desenvolvimento de um programa de tratamento. É um processo de múltiplas etapas no qual as habilidades do clínico para resolver problemas e tomar decisões têm um papel dominante (Fernandez-Ballesteros, 1994; Grossi, 2002; Haynes et al., 1997).

De acordo com Meyer (2001), é importante conhecer quais aspectos favorecem os resultados de uma terapia. Muitas vezes, quando ocorre uma intervenção falha, ou uma dificuldade na resolução do problema, faz-se uma reformulação da análise funcional para um novo planejamento de intervenção (Fernandez-Ballesteros, 1994; Grossi, 2002; Haynes et al., 1997; Sturmey, 1996).

A análise funcional possibilita a realização de uma intervenção dinâmica, pois permite que sejam analisadas as relações contingenciais que são determinantes e mantenedoras de um determinado problema, além de possibilitar a realização de estratégias de intervenção, quando necessárias, proporcionando uma intervenção eficaz para o desenvolvimento e melhora do cliente.

Este artigo tem como objetivo apresentar uma descrição a posteriori da análise funcional de um conjunto de sessões terapêuticas realizadas com uma criança de sete anos, que apresentava dificuldades de aprendizagem e de socialização, comportamentos de agressividade e de oposição. Pretende-se mostrar como o processo de intervenção aqui relatado foi guiado e modificado pela análise funcional do caso. Apresenta-se a forma como as hipóteses levantadas em cada etapa foram testadas funcionalmente, apontando-se as mudanças nos critérios comportamentais a que elas levaram e como os objetivos e estratégias empregados também se modificaram para o alcance dos resultados obtidos.

\section{Análise funcional de um caso clínico infantil}

A análise funcional deste caso clínico foi baseada em Costa e Marinho (2002), Fernandez-Ballesteros (1994), Grossi (2002), Haynes et al. (1997), Skinner (1998) e Sturmey (1996). Optou-se pela análise dos registros de trinta sessões de psicoterapia de uma criança, conforme dados abaixo. As sessões eram programadas anteriormente e, logo após cada sessão, a terapeuta fazia seus registros por escrito, descrevendo as atividades, o comportamento do cliente e a intervenção realizada.

A partir dos registros procurou-se sistematizar o atendimento, dividindo-o em quatro etapas de acordo com os diferentes focos terapêuticos (alteração dos objetivos e estratégias em função de mudanças no comportamento da criança no sentido da melhora desejada). Cada etapa foi composta pela descrição da intervenção, pela análise funcional dos dados e pela especificação dos critérios de avanço para a próxima etapa, que direcionavam as decisões de mudança no foco da intervenção.

\section{Caracterização do cliente}

M., sete anos, sexo masculino, primeiro filho, estudante da primeira série fundamental de uma escola estadual, nível socioeconômico médio.

A queixa apresentada pela família foi de que a criança estava apresentando comportamentos agressivos preocupantes na escola, assim como recusas quanto a fazer as tarefas e seguir regras em jogos e em brincadeiras. A mãe relatou que o menino "só fazia o que queria, era estúpido nas brincadeiras, não admitia perder, batia e pegava os brinquedos das mãos de outras crianças, emburrava, gritava exingava, e quando apanhava segurava o choro e parecia que ia sufocar". Nestas situações, os adultos ou cediam às suas exigências ou o deixavam ganhar, e as outras crianças se afastavam dele.

Outra queixa era a falta de atenção e concentração nas atividades escolares e a dificuldade de socialização. Durante a realização das tarefas escolares em classe, geralmente $M$. se recusava a fazer, andava pela sala, não seguia a rotina da turma e permanecia sozinho. Apresentava dificuldades específicas de aprendizagem, como juntar letras e discriminar números. A 
professora ajudava-o na realização das atividades e permitia que não as fizesse quando não queria, oferecendo outro tipo de atividade.

Em casa, M. solicitava a presença da mãe para ficar ao seu lado durante a realização das tarefas. Esperava a mãe ditar as letras das palavras para escrever e, quando não conseguia fazê-lo, desistia, empurrava o caderno, jogava o lápis no chão e verbalizava que não ia mais fazer as tarefas. Outros comportamentos de dependência também ocorriam, como esperar a mãe para enxugá-lo quando tomava banho e limpá-lo quando evacuava.

M. foi encaminhado para atendimento psicológico pela diretora da escola, que acreditava que algum "problema emocional" poderia estar atrapalhando seu rendimento escolar. Segundo a mãe, os comportamentos-problema vinham acontecendo desde que $\mathrm{M}$. ingressou na escola, há aproximadamente um ano.

A criança morava com a mãe, o padrasto e uma irmã de dois anos. A convivência com o padrasto foi considerada boa; segundo a mãe, havia trocas afetivas entre eles e a criança o chamava de pai. O pai biológico sofreu um aneurisma quando $M$. tinha dois anos; ficou hospitalizado durante dois meses e faleceu. Desde então, toda a família (avós e tios) passou a agradar muito o menino, presenteando-o semanalmente, na tentativa de fazer com que $M$. não sentisse a falta do pai.

A família morava nas proximidades da zona rural. A família estendida (tios e avós) participava muito dos cuidados diários com a criança. Desta forma, M. ingressou na escola apenas aos seis anos de idade e, durante todo o ano letivo, apresentou recusa em permanecer na sala, só ficando na presença da mãe. Por ocasião do início da primeira série, M. apresentava os mesmos problemas, embora concordasse em permanecer na escola sem a mãe. Passou a depender da companhia da prima de nove anos, recusava-se a ir à escola se ela não fosse, aguardava-a na porta da sala e permanecia com ela no recreio.

A mãe atribuiu o fato de a criança não querer fazer nada e ter dificuldades para acompanhar as atividades da primeira série a uma pré-escola"fraca", enquanto as outras crianças já entraram na primeira série semialfabetizadas. A expectativa da mãe era de que os atendimentos melhorassem o desempenho escolar de seu filho.

\section{Análise funcional do caso}

A análise funcional da situação-problema foi realizada com base nas informações coletadas da mãe. Todos os comportamentos problemáticos citados pela mesma ocorriam devido a uma história de reforçamento inadequado por parte da família.

Os comportamentos problemáticos de M. podem ser entendidos a partir das contingências que se estabeleceram em sua vida após a morte do pai. Supôs-se que a família, sem possuir padrões de comportamento que ajudassem M. a se adaptar à situação de perda, tentou compensar um provável sofrimento da criança, enchendo-a de presentes e mimos de forma indiscriminada, o que reforçou positivamente comportamentos inadequados da criança.

Provavelmente a mãe e os familiares mantinham tal conduta na tentativa de evitar que a criança entrasse em contato com situações aversivas e sofresse mais frustrações, além da que já estava vivenciando com a ausência do pai. Esta atitude da família pode ter sido temporariamente adequada, enquanto as emoções decorrentes da perda do pai estavam presentes; porém, a manutenção indefinida de tal padrão não permitiu que M. aprendesse a enfrentar situações de perda e lidar com frustrações (como perder no jogo, não ser o primeiro etc.).

O comportamento da família de ceder às suas exigências, deixá-lo vencer nas brincadeiras e de agradá-lo para acalmar suas birras favoreceu o fortalecimento de um padrão de insistência por parte da criança. Com o decorrer do tempo, pode-se dizer que os familiares caíram em uma "armadilha de reforçamento negativo", isto é, cediam ao que a criança queria (reforço positivo) como forma de se livrar (reforço negativo) da situação aversiva de "teimosia", como mostra o estudo realizado por Gardner (2006), reforçando, assim, o comportamento que desejavam suprimir e levando ao desenvolvimento de um padrão coercitivo de interação infantil (Sidman, 1995).

Com isto, a família ensinou M. a se comportar de maneira a só querer as coisas do seu jeito e na hora em que queria (ex: chamava a mãe para falar alguma coisa e, se ela não fosse na hora, ficava bravo e dizia que não falaria mais). Este padrão de comportamento pôde ser observado também durante as sessões iniciais de psi- 
coterapia, nas quais M. verbalizava:"eu sou o primeiro", "se eu perder eu paro de brincar, se você ganhar eu não vou mais brincar, hein?".

A família vinha mantendo este padrão de interação sem perceber a relação entre os seus comportamentos e os da criança (Barrero, Vollmer, Barrero \& Bourret, 2005). Como consequência, M. não aprendeu a lidar com frustrações e situações sociais. O padrão de interação, estabelecido pela família de M., favoreceu o prolongamento de comportamentos infantilizados e dependentes e uma dificuldade de adaptação a contextos sociais, como o relacionamento com colegas. Este padrão de comportamento dificultou o desempenho acadêmico de $M$.

Na escola, seus excessos comportamentais (birras, apego excessivo à mãe, comportamento opositor), favoreceram o aparecimento de deficits, como a ausência de repertório de socialização e de seguimento de instruções. Tais deficits estavam relacionados não só à falta de aprendizagem no contexto familiar, mas à idade de inserção de M. na escola.

Provavelmente as dificuldades relacionavam-se com a não preparação para o início da alfabetização, pois $M$. não teve tempo suficiente para o treino dos requisitos básicos para a aprendizagem da leitura e da escrita. Tendo que se adaptar ao contexto escolar, com novas exigências (aprendizagem, socialização), sua falta de repertório aumentava o custo de resposta, levando- o a se esquivar desta situação aversiva, recusando-se a realizar as atividades propostas. Os comportamentos concorrentes, como andar pela sala e distrair-se com outras coisas, não Ihe permitiram envolver-se de maneira adequada com os colegas e atividades propostas, o que provavelmente acarretou isolamento e rotulação negativa, que se traduziram em falta de interesse pela escola e pelas tarefas acadêmicas.

\section{Hipótese inicial}

A hipótese inicial era de que a história de superproteção familiar não favoreceu o desenvolvimento de pré-requisitos para a aprendizagem escolar e, por isso, a criança apresentava dificuldades nessa área, respondendo de modo opositor e agressivo frente às mesmas, em função do alto custo de enfrentamento destas situações. Como o menino estava na primeira série, levantou-se como hipótese que uma intervenção que focalizasse o desenvolvimento de habilidades voltadas à competência escolar poderia auxiliá-lo na superação de suas dificuldades, no nivelamento de desempenho com a turma e na consequente diminuição do comportamento opositor quanto às atividades escolares. Desta forma, esse foi o objetivo da intervenção I, descrita a seguir.

\section{Intervenção I: desenvolvendo repertório de realização de atividades escolares}

\section{Descrição da intervenção I}

O objetivo desta fase da intervenção, que teve a duração de oito sessões, foi estabelecer o vínculo entre a terapeuta e o cliente e desenvolver habilidades básicas para o desempenho escolar, como coordenação motora, discriminação visual, memória e comunicação verbal. Nesta etapa as atividades foram voltadas a desenvolver e aprimorar a competência escolar de M., isto é, levá-lo a realizar atividades, com baixo custo e bastante apoio da terapeuta e, aos poucos, aumentar a complexidade das tarefas, retirando o apoio à sua realização. As estratégias envolveram: contorno com lã das letras do nome, recorte de revista, jogos de alfabetização, jogo de memória de palavras.

Nas sessões, assim que as atividades eram iniciadas e a criança se defrontava com a primeira dificuldade, levantava-se da cadeira, negava-se a realizar a atividade, dirigia-se à janela da sala, aos armários de brinquedos e mexia nos objetos da sala. Como as atividades eram muito simples, para garantir o sucesso na realização a terapeuta insistia para que a criança retomasse de onde havia parado. Com isto, M. agredia verbalmente a terapeuta e destruía as atividades de outras crianças expostas no mural. A terapeuta então verbalizava que aquele comportamento não seria tolerado (rasgar os desenhos das outras crianças), segurava a criança firmemente e a reconduzia à mesa, sugerindo mudança de atividade. M. escolhia um jogo de sua preferência, e a terapeuta acedia.

Os jogos escolhidos geralmente eram de competição, tais como dominó e memória. Mesmo nesses jogos, de sua escolha, seu padrão de comportamento se repetia: queria ser sempre o primeiro, não seguia 
regras, andava pela sala, jogava as peças do jogo no chão e emburrava (não queria mais jogar) quando errava apenas uma jogada, não permitindo que a terapeuta continuasse a jogar. Algumas vezes em que, mesmo contrariado, aceitou permanecer no jogo, a terapeuta percebeu acentuada dificuldade na realização das tarefas relativamente simples destes jogos para crianças de sua idade (não sabia parear as peças do dominó, ou encontrar a peça do jogo de memória que tinha sido virada na jogada anterior).

\section{Análise funcional da intervenção I}

Provavelmente em função de um repertório acadêmico muito limitado, a solicitação da realização de atividades escolares pareceu ser aversiva para o cliente, o que favoreceu a apresentação de comportamentos opositores. Pode-se supor que esses comportamentos ocorriam como esquiva à exigência de desempenho, quando era solicitado à criança que fizesse algo que não sabia fazer, por exemplo: ler ou escrever uma palavra, desenhar ou montar um quebra cabeça. Pode-se supor também que a exigência, por mínima que fosse, tinha um custo elevado para a criança por causa da ausência de aprendizagem anterior; provavelmente ela se percebia incompetente frente à tarefa, irritava-se e agredia. Consequentemente, livrava-se da atividade que não queria ou não sabia fazer, conseguindo que a terapeuta mudasse de atividade e acatasse sua sugestão. A terapeuta percebeu que, assim como a família, sua atitude, embora contornasse a situação desagradável em sessão, também reforçava positivamente (deixar que ele fizesse o que queria) e negativamente (não realizar a proposta da terapeuta) o comportamento opositor e agressivo da criança, esquivando-se da situação (Gardner, 2006; Sidman, 1995).

Nesse mesmo sentido, o comportamento também era uma amostra de como a criança estabelecia suas relações com pares, pois o comportamento agressivo (bater e pegar os brinquedos da mão de outras crianças) e opositor (só fazer o que queria, ser sempre o primeiro, recusar fazer as atividades propostas) com certeza dificultava o estabelecimento de relações de amizade. Por não possuir comportamentos pró-sociais de contato afetuoso, cuidado, proteção e ajuda em relação ao outro, não sabia se comportar em situações sociais, não tinha amigos; tanto que ficava sempre na porta da sala da prima, esperando por ela, como foi citado na descrição da situação problema.

A alta frequência e intensidade dos padrões de comportamentos opositores e agressivos observados nas sessões iniciais indicaram que a intervenção precisava ser avaliada e modificada, confirmando a necessidade de um novo enquadre terapêutico; estabeleceu-se, então, a intervenção II.

\section{Hipótese para a próxima etapa}

Os comportamentos de agressão e oposição apresentados pela criança em alta frequência e intensidade na intervenção I permitiram perceber que seria necessário considerar outros aspectos de seu desenvolvimento e repertório comportamental para o delineamento de estratégias efetivas na resolução da situação problema.

Além de não apresentar pré-requisitos necessários ao desempenho acadêmico, a criança apresentava também muitos comportamentos concorrentes de oposição e de agressão, que também interferiam na adaptação escolar. Assim, a constatação deste excesso comportamental norteou uma primeira mudança na direção psicoterapêutica. Para a intervenção seguinte, passou-se a ter como objetivo o enfraquecimento deste padrão, por meio da modelagem e fortalecimento de respostas incompatíveis, como as cooperativas, recorrendo-se a atividades que necessitassem da participação do cliente e da terapeuta para a sua realização, conforme será exposto a seguir.

\section{Intervenção Il: ensinando repertório de cooperação}

\section{Descrição da intervenção II}

Nesta segunda etapa, foram realizadas seis sessões com a criança. O objetivo principal foi modelar comportamentos cooperativos e pró-sociais, criando, assim, um contexto para o fortalecimento de interações motoras e verbais agradáveis entre terapeuta e criança, como: brincar em conjunto, pedir por favor, dizer obrigado, emprestar materiais e brinquedos. Esperava-se, com isto, concomitantemente diminuir a probabilidade de ocorrência do comportamento agressivo, enfraquecendo o padrão de oposição. 
A escolha das atividades nesta etapa da intervenção foi feita com base em dois critérios: 1) nível de exigência da atividade compatível com o repertório atual do cliente, tanto verbal quanto visomotor; e 2) atividades que necessariamente requeressem ajuda mútua entre cliente e terapeuta para sua realização, tais como: massa de modelar caseira, pintura a dedo, confecção de desenhos, mosaicos e fantoches. Durante esta etapa, a terapeuta procurou direcionar bastante o comportamento do cliente, para que este pudesse obter sucesso na realização da atividade proposta. Esse direcionamento foi feito procurando-se instruir pequenas respostas, sempre valorizando seu cumprimento, por exemplo: T: "Vamos precisar da cola, você pode pegá-la para mim?"; C: pega e entrega à terapeuta; T: "Obrigada! Agora coloque um pouquinho de cola aqui"; C: realiza; T: "Isso! Esse nosso trabalho vai ficar muito bonito!"; C: olha para T e sorri; T: "Viu? Foi você que fez! Você é muito bom nesse negócio de passar cola nas figurinhas!".

Observou-se que o cliente passou a se manter por mais tempo na realização das atividades, a solicitar a ajuda da terapeuta e a apresentar interesse em saber qual seria a atividade da próxima sessão. Também foram observadas respostas de descontração, que não estavam ocorrendo anteriormente: o cliente apresentava expressão facial mais relaxada, sorria e verbalizava que estava gostando da atividade. Além de gradualmente permanecer por maior tempo na mesma atividade ao longo das seis sessões, não se negou a participar de nenhuma das atividades propostas, e demonstrava satisfação ao ver o produto final (sorria, queria expor na parede suas atividades). A terapeuta procurou reforçar cada resposta cooperativa, elogiando ou respondendo com prontidão às solicitações de ajuda do cliente e concordando com as verbalizações positivas que ele fazia sobre seu comportamento ou o produto dele, como sugere Gardner (2006).

A terapeuta também forneceu modelo de verbalizações apropriadas de solicitação de ajuda, na tentativa de, ao mesmo tempo, modelar o comportamento do cliente, fazendo com que aumentasse a probabilidade da ocorrência do mesmo, e que esta ocorrência se tornasse um pouco mais elaborada. A terapeuta também valorizava os comportamentos pró-sociais de uma forma mais indireta, verbalizando para a criança como era importante ajudar o outro quando não conseguiam fazer sozinhos, e dizendo o quanto ela estava gostando de ser ajudada e de fazer uma atividade junto com um amigo.

\section{Análise funcional da intervenção II}

A hipótese levantada ao final da primeira etapa da intervenção pareceu se confirmar, pois o objetivo de enfraquecer o padrão opositor por meio da modelagem e fortalecimento de respostas incompatíveis, como as cooperativas, foi rapidamente atingido.

A estratégia de direcionar a atividade instruindo e valorizando as pequenas respostas tinha dois objetivos: 1) evitar a ocorrência do comportamento opositor e, consequentemente, ter que lidar com respostas desagradáveis do cliente; e 2) aumentar a probabilidade de ocorrência de comportamento competente para reforçá-lo continuamente durante as sessões.

O esquema de reforço contínuo foi usado para estabelecer as respostas desejadas, e foi operacionalizado da seguinte maneira: a terapeuta auxiliava o cliente (ajudava a cortar, colar, segurar papéis, linha) imediatamente após a ocorrência de qualquer pedido mínimo de auxílio (inicialmente pequenas verbalizações do tipo "me ajuda aqui", que gradualmente foram sendo refinadas para "me ajuda aqui, porfavor"). Ao mesmo tempo em que modelava o comportamento desejado, também fornecia modelo de comportamento verbal adequado, e tais estratégias pareceram apresentar o efeito desejado, pois o cliente passou a emitir as respostas pró-sociais esperadas em sessão.

Os resultados obtidos nesta fase, tais como o aumento na frequência de interações positivas entre cliente e terapeuta, na comunicação e na participação espontânea da criança na sessão, sinalizaram que o objetivo de enfraquecimento dos comportamentos opositores foi alcançado, e que o trabalho com o repertório acadêmico poderia ser retomado. Nas duas últimas sessões desta etapa, nenhuma resposta de oposição foi observada, o que consistiu em critério para uma nova mudança no foco da intervenção.

\section{Hipótese para a próxima etapa}

A partir da análise das sessões da intervenção II, e da constatação da diminuição na frequência dos com- 
portamentos agressivos e opositores, optou-se por realizar uma nova tentativa de retomar o objetivo inicial e estabelecer outras situações em que a criança pudesse trabalhar suas dificuldades acadêmicas e, assim, minimizar os deficits apresentados. Algumas sessões adicionais de fortalecimento do padrão cooperativo poderiam ter sido feitas, mas como a criança estava muito atrasada na escola, a decisão terapêutica foi"arriscar" um retorno ao objetivo inicial, com vistas a auxiliá-la o quanto antes em suas dificuldades escolares. Assim, a transição foi programada de forma gradual, para que a criança pudesse passar de uma atividade lúdica para uma acadêmica"quase sem perceber".

\section{Intervenção III: favorecendo o desempenho acadêmico}

\section{Descrição da intervenção III}

Foram realizadas durante esta intervenção sete sessões semanais com a criança, todas com duração de sessenta minutos. As sessões consistiram em treino de atenção e de concentração e de atividades acadêmicas, visando aumentar sua competência escolar. Foram realizadas técnicas de construção de jogos de memória de sílabas, palavras e figuras, montagem de palavras, atividades de discriminação visual, leitura de livros de estórias, recorte e colagem de palavras, jogos de achar palavras e ditado.

Durante esta fase, foram observadas dificuldades acentuadas relacionadas à junção de palavras, discriminação visual e auditiva das letras. Quando eram propostas atividades acadêmicas relacionadas às suas dificuldades, o cliente iniciava, tentando fazer; quando não identificava as palavras, parava, mordia o lápis e olhava para a terapeuta (provavelmente esperando que ela ditasse as letras ou fizesse em outra folha para que ele pudesse copiar, que era como a mãe tratava o problema). Como a terapeuta não fornecia a resposta, mas tentava estimular o raciocínio, o cliente então realizava algumas tentativas de fuga da situação. As respostas observadas nesse sentido foram levantar da carteira, deitar no chão, cantarolar, rabiscar o caderno, soltar o lápis na mesa e andar pela sala demonstrando estar irritado. Às vezes, respirava fundo e verbalizava: "Ai meu
É interessante ressaltar que tais respostas foram entendidas como expressão do desagrado da criança com a situação e como tentativas de fuga do enfrentamento da dificuldade; nesse sentido, ainda constituíam comportamentos-alvo da intervenção. No entanto, também eram respostas indicativas de melhora em relação às apresentadas durante a intervenção I, pois eram menos intensas e qualitativamente diferentes: a criança agora apenas abandonava a atividade e não mais agredia a terapeuta ou destruía o ambiente.

Durante essas sessões, como as atividades eram facilitadas, mesmo "reclamando" o cliente retomava a atividade proposta pela terapeuta. A terapeuta ia tratando a fuga como "um tempo para pensar" ou "uma pausa para respirar fundo e criar coragem para continuar". Embora o cliente apresentasse avanços, estes ainda estavam sendo muito morosos, e a mãe estava relatando que a professora, embora estivesse sentindo diferença em relação aos comportamentos agressivos em sala de aula, não estava observando muitos progressos acadêmicos.

\section{Análise funcional da intervenção III}

A primeira resposta apresentada pelo menino (esperar pelas respostas a serem fornecidas pela terapeuta) provavelmente ocorria devido à sua história de aprendizagem, pois a mãe, sem saber como ajudá-lo de forma efetiva, ditava as letras das palavras e fornecia as respostas às suas dificuldades. Assim, a mãe mantinha a atitude passiva da criança frente à aprendizagem e não aproveitava tais oportunidades para o ensino de habilidades acadêmicas básicas. Em sessão, por generalização, o cliente reproduzia este comportamento e, quando a terapeuta apresentava o reforço esperado, a dificuldade da situação se intensificava e evocava o comportamento de fuga da criança. M. esquivava-se das atividades escolares apresentando comportamentos como rabiscar o caderno, jogar o lápis e andar pela sala, e seu comportamento era reforçado negativamente (Gardner, 2006).

Levantou-se como hipótese que os comportamentos de esquiva que o cliente apresentava frente às atividades que não conseguia realizar por não ter repertório para tal intensificavam ainda mais seu deficit comportamental, gerando um círculo vicioso que pre- 
cisava ser rompido: como não desenvolveu repertório básico, apresentava dificuldades acadêmicas; as falhas no desempenho escolar criavam isolamento social em relação às outras crianças; ele não se envolvia com as crianças e não adquiria repertório para enfrentar as situações de dificuldades; frente às situações de dificuldade, tanto social, quanto acadêmica, esquivava-se; e não se expunha, assim, às condições necessárias ao desenvolvimento de habilidades acadêmicas e de interação social.

Assim, embora os deficits acadêmicos e sociais estivessem correlacionados, precisariam de intervenções específicas. O cliente não apenas deveria aprender a fazer o que não conseguia em termos de conteúdo escolar, mas também a dizer que não estava sabendo, não estava conseguindo, perguntar, solicitar ajuda da professora, dos amigos, da mãe em casa. A"reclamação da dificuldade" poderia ser redirecionada para uma"solicitação de auxílio". O "Ai meu Deus, não quero fazer isso..." deveria mudar para "Aimeu Deus, alguém me ajuda a fazer isto?". Ao solicitar auxílio, as interações sociais poderiam ser facilitadas, pois receber ajuda da professora ou do colega poderia ter efeito reforçador não apenas sobre a resposta de pedir, mas sobre o início de interações sociais adequadas com outras pessoas.

\section{Hipótese para a próxima etapa}

A partir da análise funcional da intervenção III, e da constatação da dificuldade de expressividade emocional e assertividade adequadas para a idade, optou-se por realizar uma quarta modificação no curso do tratamento. Além da falta de pré-requisitos acadêmicos, uma das dificuldades concomitantes era a criança não apresentar repertório para enfrentar situações que exigiam dela a expressão de determinados sentimentos despertados pelas atividades acadêmicas (situações aversivas para o cliente) e a solicitação de auxílio à resolução de seus problemas.

Estabeleceu-se, assim, um critério claro para o início da intervenção IV: a identificação e a expressão dos sentimentos negativos da criança, dando a ela condições de enfrentar suas dificuldades, esforçando-se para realizar a atividade ou solicitando ajuda da professora e dos colegas em sala de aula.

\section{Intervenção IV: ensinando enfrentamento de dificuldades}

\section{Descrição da intervenção IV}

A partir desta etapa, em paralelo às atividades para melhorar seu desempenho acadêmico, foram trabalhados aspectos relacionados à discriminação e à expressão de sentimentos negativos frente às dificuldades enfrentadas.

O foco clínico desta etapa foi de que as habilidades de expressividade emocional (discriminar o que sentia frente à dificuldade da atividade proposta, expressar de forma adequada e solicitar apoio de forma assertiva) necessitavam ser treinadas e ensinadas, visto que os excessos comportamentais (agressividade, oposição) indicavam inabilidade em identificar os seus sentimentos frente a situações acadêmicas e lidar adequadamente com eles (Moura \& Azevedo, 2000).

Foram realizadas sete sessões com a criança, nas quais foram propostas atividades similares às da etapa anterior; no entanto, neste momento, além de realizá-las, ela deveria expressar os sentimentos em relação às dificuldades encontradas. Nesta fase da intervenção, o cliente era solicitado a dizer quando não sabia realizar a atividade e quando sentia vontade de "largar tudo" ou de "jogar tudo fora" (reações já observadas frente ao aumento gradual no nível de exigência das atividades). A terapeuta repetia essa instrução para a criança várias vezes durante as sessões, acrescentando que era importante que ela verbalizasse quando uma dessas coisas acontecesse para poder auxiliá-lo.

Quando o cliente emitia a resposta solicitada, a terapeuta procurava elogiar seu comportamento e mostrar sua importância, para que fosse possível perceber que ele precisava de ajuda. Em seguida, a terapeuta o auxiliava minimamente, até o ponto em que ele conseguisse prosseguir e finalizar a atividade proposta. Neste momento, a terapeuta valorizava a conclusão da tarefa, relacionando-a ao seu comportamento anterior de expressar seus sentimentos e solicitar ajuda frente às dificuldades, dizendo que agora que ele aprendeu um "novo jeito de fazer tarefas difíceis", ele poderia usar sua nova habilidade na escola também. 


\section{Análise funcional da intervenção IV}

Pôde-se perceber nas intervenções anteriores que M. não sabia como se comportar de maneira adequada em situações que envolviam atividades escolares, sendo que era nestas situações que ele mais apresentava comportamentos agressivos (empurrar a folha, negar-se a realizar atividades, jogar o lápis, morder o material e xingar). Na intervenção IV, a terapeuta foi criando contingências para que a criança se expressasse verbalmente, incentivando e dando modelo do que fazer e do que falar quando não conseguisse fazer uma atividade. A expressão verbal negativa não apenas foi permitida, mas também ensinada ("não há problema não saber e dizer que não sabe, o problema é agredir por causa disso e não pedir ajuda"), e a emissão das respostas adequadas teve como consequência o apoio parcial da terapeuta, tornando não apenas mais fácil a realização das atividades, mas, também, mais provável o comportamento de solicitar ajuda.

Assim, observou-se diminuição na frequência de ocorrência dos comportamentos de esquiva apresentados pelo cliente nestas atividades. O cliente passou a verbalizar que"não sabia", que sentia"vergonha quando via os outros alunos fazendo o que ele não conseguia", que "não gostava de fazer tarefas difíceis", e que "não gostava nem de tentar". Com a aprendizagem da expressão adequada dos sentimentos negativos decorrentes da dificuldade em realizar uma atividade, criaram-se condições para que a terapeuta reforçasse os comportamentos de expressividade emocional da criança e modelasse comportamentos de enfrentamento das situações de dificuldades e finalização de tarefas.

No decorrer dos atendimentos, a terapeuta apresentava condições para aumentar a expressão de sentimentos, inclusive os de raiva (quando não conseguia fazer o que queria ou uma atividade, ou quando perdia o jogo), uma vez que sinalizava a não ocorrência de punição para tais comportamentos. Pôde-se, então, ensinar ao cliente novas formas de atuação frente a situações difíceis. Assim, o processo psicoterapêutico ajudou o cliente a aprender novas formas de atuação frente a situações nas quais não se comportava adequadamente por falta de repertório (Bussad, 1997).

A criança passou a realizar as tarefas acadêmicas

182 propostas nas sessões ao invés de esquivar-se delas, e solicitar ajuda para enfrentar as dificuldades encontradas. A mãe relatou melhora da criança em casa e na escola. A professora informou que M. estava respeitando mais as regras dos jogos, das brincadeiras e das normas de convivência social, e que seu desempenho acadêmico já estava compatível com a média da turma.

As análises das sessões foram encerradas nesta etapa. O cliente ainda foi acompanhado por algum tempo, mas como essas sessões tiveram o objetivo de fortalecer os ganhos obtidos, não foram incluídas nesta análise, por se considerar que as etapas de intervenção estavam encerradas.

\section{Considerações Finais}

Considerando-se que o processo de tomada de decisão em psicoterapia ainda é um tópico de estudo e discussão, este trabalho se propôs a descrever o que foi realizado terapeuticamente com um cliente infantil dentro do contexto clínico, e por que tais decisões foram tomadas. Considerou-se que a análise funcional poderia permitir uma melhor descrição e consequente entendimento quanto às variáveis importantes que direcionaram as tomadas de decisão dentro do caso descrito. Assim, a análise funcional foi empregada durante todo o processo terapêutico e posterior análise descritiva com o objetivo de verificar se as intervenções estavam atingindo os resultados a que se propunham.

Esta metodologia de análise pareceu favorecer a identificação mais clara dos critérios comportamentais que permearam as mudanças nos objetivos e nas estratégias de intervenção, o que parece ter auxiliado na explicitação do processo de tomada de decisão dentro do caso. A descrição passo a passo das análises e das hipóteses que nortearam a intervenção realizada pareceu ser uma contribuição deste estudo, pois os terapeutas podem não discriminar em função de que variáveis tomam determinada decisão se não a descreverem verbalmente.

Observou-se que o teste das hipóteses levantadas durante as intervenções possibilitou um melhor direcionamento da intervenção terapêutica, de modo que foi possível identificar quando parar, prosseguir ou mudar o foco da intervenção, possibilitando o levanta- 
mento de informações para se cogitar novas hipóteses e auxiliar o cliente. Por fim, constatou-se que a análise e a sistematização funcional do caso a posteriori permitiram avaliar erros e acertos e estruturar uma tecnologia psicoterapêutica dinâmica e eficiente, que pode ser replicada em outras situações clínicas.

\section{Referências}

Bussad, V. S. R. (1997). O desenvolvimento de comportamentos pró-sociais na criança: considerações sobre a natureza dos fatores e dos processos envolvidos. Temas de Psicologia, 3 (1), 19-26.

Barrero, C. W., Vollmer, T. R., Barrero, J. C., \& Bourret, J. (2005). A method for evaluating parameters of reinforcement during parent-child interaction. Research in Development Disabilities, 26 (6), 577-579.

Costa, S. E. G. C., \& Marinho, M. L. (2002). Um modelo de apresentação de análise funcional do comportamento. Estudos de Psicologia (Campinas), 19 (3), 43-54.

Delitti, M. (1997). A análise funcional: O cliente como foco de análise. In M. Delitti (Org.), Sobre comportamento e cognição: a prática da análise do comportamento e da terapia cognitivo-comportamental (Vol 2, pp.37-44). São Paulo: ARBytes.

Fernandez-Ballesteros, R. (1994). Psychological assessment. Applied Psychology: An International Review, 43 (2), 157-174.

Gardner, A. W. (2006). An evaluation of the interaction between quality of attention and negative reinforcement with children displaying escape-mantained behavior. Dissertation Abstracts International: Section B: The Sciences and Engineering, 66 (8-B), pp.4469.

Grossi, R. (2002). Análise Funcional de uma proposta de atendimento domiciliar. Um estudo de caso de uma família, com filho adolescente portador de autismo e com muitos problemas comportamentais. Tese de doutorado nãopublicada, Universidade de São Paulo.

Hagopian, L. P., Fisher W. W., Thompson, R. H., Owen-Deschryver, J. O., Iwata, B. A., \& Wacker, D. P. (1997). Toward the development of structured criteria for interpretation of functional analysis data. Journal of Applied Behavior Analysis, 30 (2), 313-326.

Haynes, S. N., Leisen, M. B., \& Blaine, D. D. (1997). Design of individualized behavioral treatment programs using functional clinical case models. Psychological Assessment, 9 (4), 334-348.

Kodak, T., Grow, L., \& Northup, J. (2004). Functional analysis and treatment of development for a child with attention deficit hyperactivity disorder. Journal of Applied Behavior Analysis, 37 (2), 229-232.

Meyer, S. B. (1997). O conceito de análise funcional. In M. Delitti (Org.), Sobre comportamento e cognição: a prática da análise do comportamento e da terapia cognitivo-comportamental (Vol. 2, pp.31-36). São Paulo: ARBytes.

Meyer, S. B. (2001). A relação terapeuta-cliente é o principal meio de intervenção terapêutica? In H. J. Guilhardi, M. B. B. P. Madi, P. P. Queiroz \& M. C. Scoz (Orgs.), Sobre comportamento e cognição: expondo a variabilidade (Vol.8, pp.95-98). Santo André: ESETec.

Moura, C. B., \& Azevedo, M. R. Z. S. (2000). Estratégias lúdicas para uso em psicoterapia comportamental infantil. In R. C. Wielenska (Org.), Sobre comportamento e cognição: questionando e ampliando a teoria e as intervenções clínicas em outros contextos (Vol.6, pp.163-170). Santo André: ESETec.

Moura, C. B., \& Venturelli, M. B. (2004). Direcionamentos para a condução do processo terapêutico comportamental com crianças. Revista Brasileira de Terapia Comportamental e Cognitiva, 6 (1), 17-30.

Sidman, M. (1995). Coerção e suas implicações. Campinas: Editorial PSY.

Skinner, B. F. (1974). Sobre o behaviorismo. São Paulo: Cultrix.

Skinner, B. F. (1998). Ciência e comportamento humano (10a ed.). São Paulo: Martins Fontes.

Sturmey, P. (1996). Functional analysis psychology. London: John Wiley \& Sons.

Recebido em: 24/8/2007

Versão final reapresentada em: 11/2/2008

Aprovado em: 11/3/2008 
